San Franc1sco, Cal1fornta

March 3-7, 1985

\title{
SURFACE EFFECTS ON SPUTTERED ATOMS AND THEIR ANGULAR AND ENERGY DEPENDENCE
}

\author{
Ahmed M. Hassanein \\ Fusion Power Program, Argonne National Laboratory \\ 9700 South Cass Avenue, Argonne, I111nois 60439 U.S.A. \\ (312) $972-5889$
}

Submitted Apr11 1985

For publication in FUSION TECHNOLOGY

\section{DISCLAIMER}

This report was prepared as an account of work sponsored by an agency of the United States Government. Neither the United Staies Government nor any agency thereof, nor any of their employees, makes any warranty, express or implied, or assumes any legal liability or responsibility for the accuracy, completeness, or usefulness of any information, apparatus, product, or process disclosed, or represents that its use would not infringe privately owned rights. Reference herein to any specific commercial product, process, or service by trade name, trademark, manufacturer, or otherwise does not necessarily constitute or imply its endorsement, recommendation, or favoring by the United States Government or any agency thereof. The views and opinions of authors expressed herein do not necessarily state or rellect those of the United States Government or any agency thereof. 


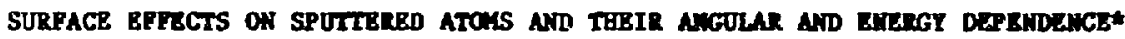

\author{
Ahued M. Hassanein \\ Fusion Power Program, Argonne National Laboratory \\ 9700 South Cass Avenue, Argonne, Ill1nols 60439 U.S.A.
}

(312) $972-5889$

\begin{abstract}
A cotaprehensive three-dimensional Monte Carlo computer code, Ion Transport in Materials and Compounds (ITMC), has been developed to study In detall the surface related phenomena that affect the amount of sputtered atoms and backscattered lons and their angular and energy dependence. A number of Iaportant factors that can significantly affect the eputtering behavior of a surface can be studied in detall, such as having̈ different surface properties and composition than the bulk and synergisilc effects due to surface begregation of alloys. These factors can be laportant in determining the lifetime of fusion reactor first walls and limiters. The IMMC Code 18 based on Monte Carlo methods to track down the path and the damage produced by charged part 1cles as they slow down in solid wetal surfaces ot compounds. The major advantages of the ITMC code are its flexibility and ability to use and compare all existing models for energy losses, all known interatomic potentials, and to use different materials and colspounda with different surface and bulk composition to allow for dynamic surface composition changes. There is good agreement between the code and avallable experimental regults whout using adjusting parameters for the energy losses mechanisms. The ITMC Code is highly opt1nized, very fast to run and easy to use.
\end{abstract}

\section{INTRODUCTION}

The behavior of energetic lons in solids has long been studied both theoretically and experimentally for many years. The theoret1cal understanding of atontc-displacement effects in solids requires a detalled analysis of the physical processes involved in slosing down the Incident lons. Two major theoretical methods are used to describe ion transport in a solid, f.e., the analytical approach and the Monte Carlo simulation process. The analyt 1cal method is based on the transport theory approach with special simplifying assumptions

\footnotetext{
*Work supported by the U.S. Department of Energy.
}

In order to wake the probles easy to solve. Th1s approach is usually restricted to certain applications and spectal cases. The rionte Carlo method 10 based on conputer simulation of the scattering process and the slowing down of the Incident particles in target naterials. This technique has been extensively applied tc the sinulation of fon transport and slowing dow. 1-5 The increasing popularity and variety of Monte Carlo calculation in the 11terature 18 due to aeveral factors. One of these factors is the capability to siaulate trafectories in cowplex configurations such as film/ substrate targets with different alloy compositions. Another factor is the varlety of the processes that can be studied with fine detalls such as range calculations, sputtering and backscattering coefficients and their energy and angular distributions. However, an important factor is the avallability of Iarge digital computers and fast processors that can actually compete with other analytical methods.

In this paper the exrential fealures of the Monte Carlo computer code ITHC are reviewed. A core detalled description of the Code and 1 ts capability are given in Ref. 6 . The code can be used to study 1 on penetration and danage produced in solids for varlous 1ontarget combinations wth target naterials being aingle eleaent or allog. The alloy can have different surface and bulk comositions due to possible Gurface segregation effects. Ion and energy reflection coefficlents a well as their angular and energy dependence can also be studied. Sputtered atom, thelr energy and angular distribution, and the location inside the rarget fron wich they are sputtered can be calculated for each aton species of the target. The individual contribution of priagry and secondary knock-on atoms to the tota? sputtering yleld can also be evaluated for each atow 6pecies. Alaost all the known interatomic potentials can be used to calculate the nuclear scattering cross sections. Switching from one potential to another at certain energies is easily done to study the effect of the interatomic potential on range, sputtering, and backscattering calculations. The influence of the Inelastic 
energy loss on varlous calculations can be studied by using different models for the slowlig down of particles in the carget.

\section{BASIC ASSUMPTIONS}

In the Monte Carlo calculation, physical quantitles such as ion penetration depth, backscattering and sputtering yields and their spatial, energy, and angular distributions are evaluated from the simulation of the scattering events occurring in a large number of sioulated fon trajectories within the target. Thus, the accuracy in calculation depends on the number of trajectories used as well as how precisely the calculation simulates the actual complicated trajectorles in the target. In the present calculation, like most Honte Carlo aethods, the scattering process is strulated on the following major assumptlons:

(1) the atoms are arranged randomly in the target, l.e., no lattice directional properties are considered;

(2) the collision between an incident ion and any target atom is binary wth no influence of nelghboring atoms; and

(3) the moving particle loses energy continuously to electrons while traveling between successive collistons at which nuclear losses occur.

\section{CALCULATION PROCEDURE}

A brlef sumary of some of the models used in the code is presented here. The formulations used for nuclear scattering and energy loss and the electrontc stopping power are given below.

\section{Nuclear Scattering}

The universal differential scattering cross-section given by LSS theory $1 \mathrm{~s}^{7}$

$$
\text { do }-\pi a^{2} \frac{t\left(t^{1 / 2}\right)}{2 t^{3 / 2}} d t
$$

where

$$
\begin{gathered}
t^{1 / 2}=\varepsilon \sin (\theta / 2), \\
\varepsilon=\text { reduced energy }=\frac{M_{2}}{\left(M_{1}+M_{2}\right)} \frac{a}{z_{1} z_{2} e^{2}} E,
\end{gathered}
$$

and $\theta$ is the scattering angle in the center of wass system. $M_{1}$ and $Z_{2}$ are the atonic wass and number respectively for Incident lon; subscript 2 is for target atom.

by:

The acreening paraneter, a, can be glven
LIndhard ${ }^{7}$

$$
\begin{aligned}
& a=0.8853 a_{0}\left(z_{1}^{2 / 3}+z_{2}^{2 / 3}\right)^{-1 / 2}, \\
& P 1 \text { [800 } 8
\end{aligned}
$$

$$
a=0.8853 a_{0}\left(z_{1}^{1 / 2}+z_{2}^{1 / 2}\right)^{-2 / 3},
$$

where $a_{0}=0.529 \mathrm{~A}$ 18 the Bohr radius.

The universal scatcering function $f\left(t^{1 / 2}\right)$ can be written as 9

$$
f\left(t^{1 / 2}\right)=\lambda t^{1 / 2-m}\left[1+\left(2 \lambda t^{1-a}\right)^{q}\right]^{-1 / q} .
$$

where the coefficlent $\lambda, a$, and $q$ are fitting paraneters adjusted for different interatonle potentiala as hown in Table 1 . Although the extrapolation of this scattering funcelon ay not be accurate at low values of energy, the cross sections are only used on a relative bas1s. At low energies where the screening effect becomes nore effective, the Born-Hayer (BM) potential is used. The scattering function for this potential is given as ${ }^{10}$

$$
f\left(t^{1 / 2}\right)=24 t^{1 / 2}
$$

The energy below which this potential can be used 18 estlaated to be

$$
E_{a}=2.23 \mathrm{Z}_{1} \mathrm{Z}_{2} \mathrm{e}^{2} \frac{\left(M_{1}+M_{2}\right)}{M_{2}} \mathrm{a}^{2} .
$$

A combination of any of the potentials shown in Table I and BM pocential can be used in calculating the nuclear-scattering cross section. The total scattering cross section $\sigma_{T}$ is then given by

$$
\sigma_{T}=\int_{t_{\min }^{1 / 2}}^{t_{\max }^{1 / 2}} d \sigma .
$$

where

$$
\begin{aligned}
& t_{\max }^{1 / 2}=E \sin \frac{\pi}{2}=E \\
& t_{\min }^{1 / 2}=E \sin \frac{\theta_{\min }}{2} .
\end{aligned}
$$

The mininum angle of scatcering $\theta_{\text {gin }}$ can be deternined fron Eq. (8) assuming that

$$
\sigma_{T}=\sum_{j}^{N T} N_{j}^{2 / 3}
$$


TABLE I

The Coefficients of the Uriversal Scattering Function 4,11

\begin{tabular}{|c|c|c|c|c|}
\hline & Potential & $\lambda$ & 田 & $\mathbf{q}$ \\
\hline 1. & $\begin{array}{l}\text { Thomas-Fermi- } \\
\text { Sommerfeld (TFS) }\end{array}$ & 1.7 & 0.311 & 0.588 \\
\hline 2. & Bohr (B) & 2.37 & 0.103 & 0.570 \\
\hline 3. & Lenz-Jense (LJ) & 2.92 & 0.191 & 0.512 \\
\hline 4. & Mollere (MOL) & 3.07 & 0.216 & 0.530 \\
\hline & Thomas-Fermi (TF) & 1.309 & 0.333 & 0.667 \\
\hline b. & Wilson (W) & 3.35 & 0.2328 & 0.4445 \\
\hline 7. & $\begin{array}{l}\text { Kalbitzer and } \\
\text { Oetzmann (KO) }\end{array}$ & 2.54 & 0.25 & 0.475 \\
\hline
\end{tabular}

where $N_{j}$ is the atom density of type $j$ and NT is the total number of species in a polyatomic target. The scattering angle $\theta_{1}$ after collision (1) is determined from a uniform random number $R_{1}\left(a \leq R_{1} \leq 1\right)$, where

$$
R_{1}=\sigma\left(c^{1 / 2}\right) / \sigma_{T} \text {. }
$$

The numerlcal methods used in detenoining both $\theta_{\mathrm{min}}$ and $\theta_{1}$ are highly optimized and very accurate and are described in detall in Ref. h. The aztruthal scattering angle $\phi !$ is determined from another uniform random number $R_{2}$ where

$$
\nabla_{1}=2 \pi R_{2} \quad\left(0 \leq R_{2} \leq 1\right) .
$$

The nuclear energy 1088 at each collision can then be calculated as

$$
\Delta E_{n}=\frac{4 M_{1} M_{2}}{\left(M_{1}+M_{2}\right)^{2}} E \sin ^{2} \frac{\theta_{1}}{2}
$$

\section{B. Electronic Energy Losa}

Four different madels for the electronicstopping crose sections can be used to calculate the inelastic energy loss during particle slowing down. These models are Lindhard-gtopping formula, Bethe-Block equation, Brice seri-empirical correlation, and zlegler-fitting coefficients. The lindhard formula is usually used in the low energy regime and the stopping power per unit length is glven by

$$
s_{L}=K_{L} E^{1 / 2}
$$

where
$K_{L}=z_{1}^{1 / \epsilon}\left[\frac{0.0793 z_{1}^{1 / 2} z_{2}^{1 / 2}\left(A_{1}+A_{2}\right)^{3 / 2}}{\left(z_{1}^{2} / 3+z_{2}^{2 / 3}\right)^{3 / 4} A_{1}^{3 / 2} A_{1}^{1} / 2}\right]$.

The Bethe equation is used for Incldent Ion velocit1es $\left.v>v_{0} 2\right\} / 3$, where $v_{0}$ is, Bohr velocity. The stoppling power is given by ${ }^{1}$

$$
S_{B}=\frac{8 \pi z_{1}^{2} e^{4}}{I_{0} \epsilon_{B}} \ln \varepsilon_{B}
$$

and

$$
\varepsilon_{B}=4 \frac{m_{e}}{H_{1}} \frac{E}{Z_{2} I_{0}} \text {, }
$$

where $\left(z_{2} I_{0}\right)$ is the mean exc1tation energy and $\mathrm{w}_{e} 1 \mathrm{~s}$ the electron mass. The mean ionization potential, $I_{0} 1 \mathrm{~s}$ given by 12

$I_{0}= \begin{cases}12+7 z_{2}^{-1} \text { ev } & z_{2}<13 \\ 9.76+58.5 z_{2}^{-1.19} \text { ev } & z_{2} \geq 13 .\end{cases}$

The Brice 13 formula which contalns three fitting parameters for each lon-carget combination for a wide range of energy can also be used to calculate the electronlc stopping. For light lons the ziegler ${ }^{14}$ fitting coefficlents can also be used to calculate the electronic losses for a wide range of energy.

The motion of the licident particle between collisions $1 \mathrm{~s}$ simulated as free flights of certain length, $\delta$, where the particle loses energy due to electrons. The step length between collisions can be asaumed elther constant or proportional to the mean free path, 1.e.,

$$
\sigma \cdot=\sum_{j}^{N T} N_{j}^{-1 / 3}
$$

or the step length can be calculated frow a uniform random number $R_{3}$ as

$\delta=-\sum_{j}^{N T} N_{j}^{-1 / 3} \ln R_{3} \quad\left(0<R_{3} \leq 1\right)$.

Then the electronic energy loss $\Delta \mathrm{E}_{\mathrm{e}}$ is simply

$$
\Delta E_{e}=\sum_{j}^{N T} N_{j} s_{j},
$$

where $s_{j}$ is the stoppling power for atom 
In a fixed frame of reference, the direction cosines of the particle velocity vector Tust be calculated after each collision. Let $\left(\alpha_{1}, \beta_{1}, \gamma_{1}\right)$ be the direction cosine of the parifcle after the 1-th collision. It can be easily ghown that

$$
\begin{aligned}
{\left[\begin{array}{l}
a_{1} \\
\beta_{1} \\
\gamma_{1}
\end{array}\right] } & =\left[\begin{array}{l}
a_{1-1} \\
\beta_{1-1} \\
\gamma_{1-1}
\end{array}\right] \cos \theta_{1}^{*} \\
& +\left[\begin{array}{l}
-\beta_{1-1} \\
a_{1-1} \\
0
\end{array}\right] \frac{\sin \theta_{1}^{*} \cos \phi_{1}}{\sqrt{1-\gamma_{1-1}^{2}}} \\
& +\left[\begin{array}{l}
-a_{1-1} \gamma_{1-1} \\
-a_{1-1} \beta_{1-1} \\
1-\gamma_{1-1}^{2}
\end{array}\right] \frac{\sqrt{1-\theta_{1}^{*}} \theta_{1 n} \phi_{1}}{\sqrt{1-\gamma_{1-1}^{2}}},
\end{aligned}
$$

where $\theta_{1}^{*}$ is the scattering angle in the laboratory system, and is given by

$$
\cos \theta_{1}^{\star}=\frac{M_{1}+M_{j} \cos \theta_{1}}{\left(M_{1}^{2}+2 M_{1} M_{j} \cos \theta_{1}+M_{j}^{2}\right)^{1 / 2}} .
$$

The position of the particle at the point of collision, 1 , is then given by

$$
\begin{aligned}
& x_{1}=x_{1-1}+a_{1-1} \delta \\
& y_{1}=y_{1-1}+\beta_{1-1} \delta \\
& z_{1}=z_{1-1}+\gamma_{1-1} \delta
\end{aligned}
$$

\section{SIMULATION OF KNOCK-ON CASCADE AND SURFACE EFFECTS}

For polyatonic targets prior to each collision, a random number is generated to decide the type of atom to be collided with. The probability of collision can be calculated assuming different cross-section models. It is assumed in this calculation that the probability of collision 18 proportional to the atomic density of the specles. If any target ator $(j)$ recelves an energy $E^{j}=\Delta E_{n}>$ fd (displacement energy of atom $j$ ) and also $E^{j}$ ) $E_{b}^{j}$ (binding energy of atom $j$ ), this atom will be set in motion with an energy $E^{J}=\Delta E_{n}-E_{b}^{j}$ and undergo simllar scattering events as the incident particle and a cascade 13 generated. The recolled ator in a cascade continues to wove, losing lts kinetic energy through both elastic and inelastic scattering, uncil its energy falls below a cut-off energy
$E_{C}^{J}$ (usually gosued equal to the surface binding energy $\mathrm{E}_{\mathrm{s}}^{3}$ ) or it leaves the eurface as a sputtered atom. For an aton to leave the surface it has to overcowe a surface barrier $U$, Two different wojels can be used to calculate U. The spherical model in which $\mathrm{u}^{J}=\mathrm{E}_{\mathrm{s}}^{\mathrm{J}}$, and the planar model wich is used in this calculation, in which $\mathrm{u}^{j}=\mathrm{B}_{\mathrm{g}} / \cos ^{2} \theta_{\mathrm{f}}$, where $\theta_{\mathrm{J}}$ is the ejection angle of the sputtered atom j. In the ITHC code it is assured that atous trying unsuccessfutly to leave the surface with energy $E^{j}<j^{j}$ but with enough energy $E^{J}$ $>$ E WIl be reflected back Into the target as if they were reborn again at the surface with incldent energy equal to $\mathrm{B}^{j}$ and incldent angle $\theta_{f}$. These atous will be followed until their energy falls below $E_{c}$ or successfully, leave the surface. However, if $\mathrm{E}^{\mathbf{j}}<\mathrm{U}^{j}$ and $\mathrm{E}^{\mathrm{J}}<\mathrm{E}$, these atoms are assumed to be burled in the surface layer.

\section{RESULTS AND DISCJSS_ON}

\section{A. General Applications}

Several examples demonstrating the validity of the code for various calculations using different lon-target conblnations and compared wth avallable experimental data and other known codes are given in Ref. 6. In this paper we exanine sone of the factors that can affect the sputtering yleld due to surface and other related phenonena. One factor is the choice of potential to calculate the nuclear scattering cross section. There are several potentials developed during the past to describe the atonic interaction as ohown in Table 1. However, it 18 difficult to find an interatouc potential that describes such an interaction of any lon-target combination in all energy ranges. For example, it is known that TF potential overestiases the sereening effect of the outer electrons especially at low energy, leading to a shorter range in target aterials. Therefore, in these calculations the TP potential is used at higher energles and below certain energy, $E_{0}[(E q .(7 b)]$, the BM potential is used. The effect of the choize of potential on the sputtering gleld of slilcon target bombarded by argon long with different energies $1 \mathrm{~s}$ shown in $1 \mathrm{~g}$. 1. The cholce of argon-silicon conbination 18 asde because of the nany avallable experimental data to conpare wth. The combination of $\mathrm{TF}+\mathrm{BM}$ potentials yield the best sputtering result conpared with two experiaental sets of data, 1.e., Rang et al, 15 and Southern et al.16 At low lon energy of 1 keV the s111con sputtering yleld predicted by $\mathrm{MOL}, \mathrm{LJ}$, and $\mathrm{OR}$ potentials is about factor of two to three lower than that given by $T F+B M$ or the experimental dita. Although there are no significant differences in the electronic and nuclear energy losses and the average number of priary recoil cascade anong these potentials. the large difference in the sputtering yield 


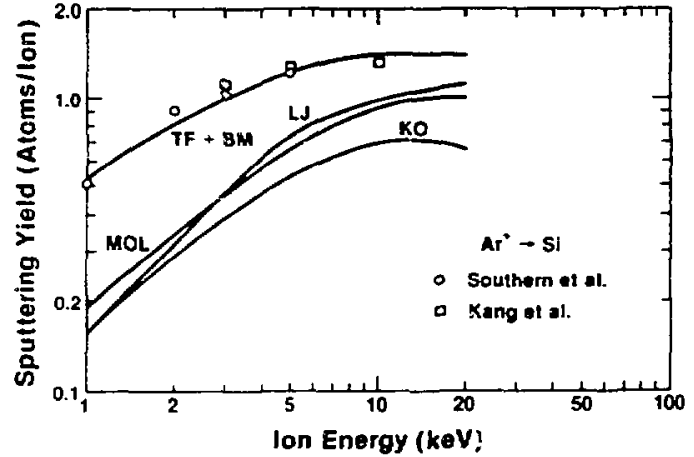

Fig. 1. Silicon sputtering yield as a function of argon ton elergy for different interatonic potentials.

Is mainly attributed to the fact that these cascades are generated near the surface in the case of $T F+B M$ potent1al. 6 The lon range predicted by $W$ potential is about $40 \mathrm{z}$ higher (at $10 \mathrm{kev}$ ) than $T F$ potent lal with or without BM combination and is about a factor of two higher at lower energy (at $1 \mathrm{keV}$ ). The MOL and ko potentials yield a slightly higher range of 15 to $20 \%$ than the TF potential.

The sllicon sputtering yleld as a function of angle of incidence is show in Fig. 2 for two different argon energies. The agreement is again very good between the code prediction using $T F+B M$ potential and the experimental data.

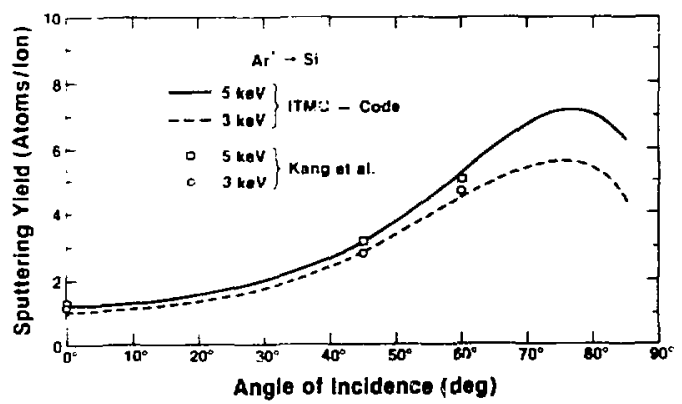

Fig. 2. Silicon sputtering yleld as a function of argon lons angle of Incidence.

The values of the displacement energy, binding energy, and surface energy can stignificantly affect the sputtering yield calculation. These values not only are scarcely known but also change with continuous ion bombardinent as a result of damaged target structure. Th1s fact should be considered in est1roating the lifetime of a liulter or filrst wall of a fusion reactor espectally when erosion and redeposition of target material are

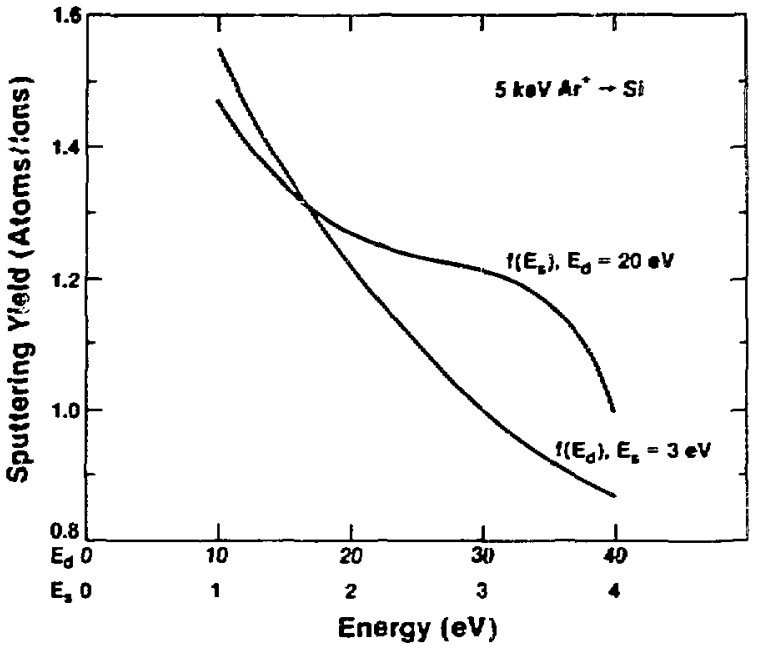

F1g. 3. Variations of sputtering yield with surface and displacenent energies.

expected to occur. As an example, Fig. 3 shows the varlation of the sputtering yield as a function of the surface and displacement energy for a fixed binding energy. The yteld can easily vary by 30 to $40 \%$ with a slight variation in these energies. In ITMC code values, these energles need to be supplied and are not neglected as in other codes; no other adjusting parameters are used for the energy losses just to yield comparable results with the experiments. The values used for these energies are given in Ref. 6 .

\section{B. Surface Effects Due to Alloy Segration}

A self-sustalning low-z coatings for fusion applications involves the use of alloys In which themal and radiation-related segregation that results in surface overlayers have been proposed. 17 These overlayers entirely consist of the low- $z$ component. Several alloys for candidate fusion reactor materials have been demonstrated as capable of producing such overlayers (e.g., Cu-LI, $\mathrm{H}-\mathrm{Be}$, and VaAl). 18 These low- $z$ layers act as a plasma shield from the high-z component of the alloy that could seriously affect plasea perforaance. One of these alloys is the vanadiumaluminum alloy ( $90 \mathrm{Z} \mathrm{V}-10 \mathrm{Z}$ Al at. $\mathrm{K}$ bulk cosposition) in which the aluminum segregates and forms monolayers of pure aluminum on the surface. Figure 4 shows the vanaditir selfaputtering yleld for pure vansdiun target and for vanadium-alumi num alloy with one and three monolayers of aluminum on the surface. The vanedium self-sputtering yield with one monolayer of aluninum on the surface is reduced by about a factor of two than that of pure vanadium. With chree monolayers the self-sputtering Is reduced by a factor of four at the low energy and by a factor of three at the high 
energy shown in Fig, 4 and the self-sputtering yleld does not exceed unity for energies up tc $5 \mathrm{keV}$. The energy spectrum of the sputtered vanadium and aluminum atoms without and with aluminum on the surface for $1 \mathrm{keV}$ incident vanadium lons are shown in Figs. 5 and 6 , respectively. If there is no aluminum surface layer, the spuctering yield of aluminum is only about $14 \%$ of the total yield (r.he total yield is roughly equal to that of pure vanadium). On the other hand, when three monolayers of aluminum exist on the surface, the aluminum sputtering yield 18 about $75 \%$ of the total yield while the vanadium self-sputtering

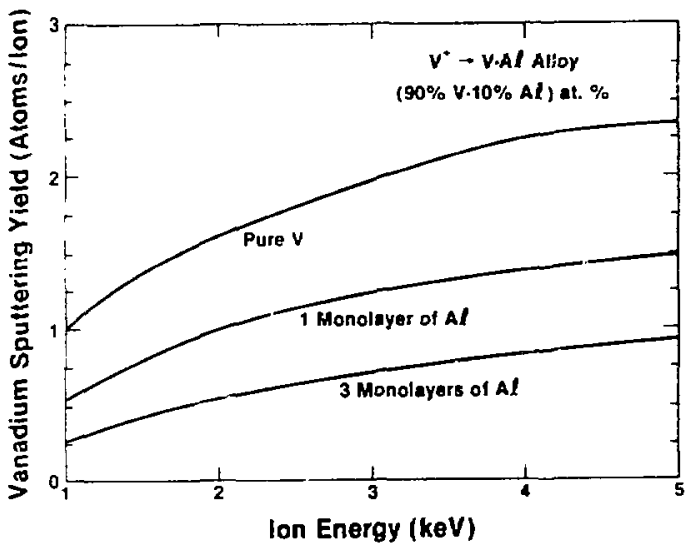

Fig. 4. Vanadium sputtering yleld due to aluminum segration at the surface.

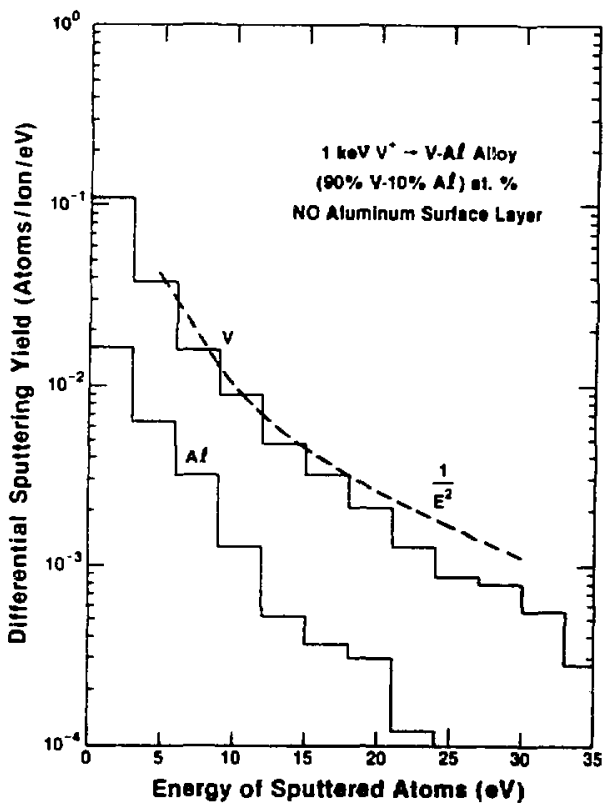

FIg. 5. Sputcered atow energy spectra with no aluminum on the surface.

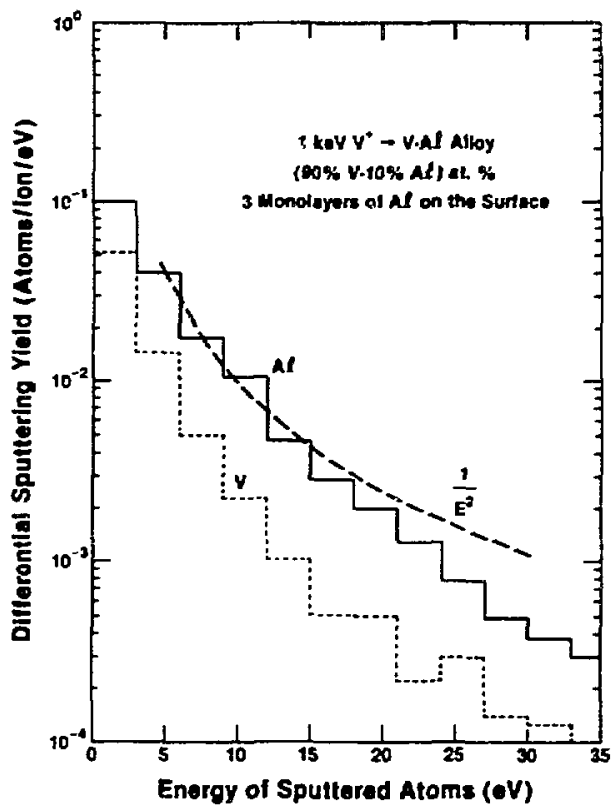

F1g. 6. Sputtered atoms energy spectra with three monolayers of aluminum on surface.

Is only $25 \%$ of the total yield. In both cases the energy spectrum of the total sputtering atoms obeys the theoretical $\mathrm{E}^{-2}$ predictions falrly well.

\section{SUMMARY AND CONCLUSIONS}

A comprehenaive three-dimensional Monte Carlo computer code (ITMC) has been developed to study Ion penetration and its related phenomena in single eleaents or alloys with different multilayers of polyatomis materials having different surface and bulik composition. The code includes a vartety of models to calculate the elastic and Inelastic energy losses during lon slowing down in target naterials. The code is highly optioized, fast to run, and easy to use. The agreement between the code and avallable experimental data 13 very good.

\section{REFERENCES}

1. J. P. BIERSACK and L. G. HAgGMARK, Nucl. Instr. and Meth. 174, 257 (1980).

2. O. S. OEN, D. R. HOLMES, and M. T. ROBINSON, J. App1. Phys. 34, 302 (1963).

3. T. ISHITANI, R. SHIMIZA, K. MURATA, Jap. J. AppI. Phys, I1, 125 (1972).

4. I. ADESIDA and L. KARAPIPERIS, Rad. Eif. 61,223 (1982). 
5. H. M. ATTAYA, Ph.D. Thesis, University of Wisconsin-Madison, Report, UWFDH-420 (Hay 1981).

6. A. M. HASSANEIN, "Ion Transport In Materials and Compounds - The ITMC-Code," Argonne National Laboratory, ANL/FPP-TR-199 (1985).

7. J. LINDHARD, v. NIELSON, and M. SCHARPF, Mat. Pys, Yedd. Dan. Vid. Selsh. 36, 10 (1968).

8. 0. B. FIRSOV, Zb. Bkap. Teor. Fiz. 33, 696 (1957) or Soviet Phys. JETP 6, 534 (1958).

9. K. B. WINTERBON, P. SIGMUND, and J. B. 'iANDERS, Mat. Fy8. Medd. Dan. Vid. Selsk. 37, $14(1970)$.

10. P. SIGMUND, Phys. Rev. 184, 383 (1969).

11. K. B. WINTERBON, Rad. Eff. 13, 215 (1972).

12. R. STERNHEIMER, Phys. Rev. 145, 247 (1966).

13. D. K. BRICE, Phys. Rev. 6, 1971 (1972).

14. H. ANDERSON and J. ZIEGLER, "Hydrogen and Heiluid Stopplng Powers and Ranges in All Elements (Pergamon Press, New York, 1977).

15. S. KANG, R. SHIMIZU, and T. OKUTANI, Japanese J. App1. Phys. 18(9), 1717 (1979).

16. A. SOUTHERN, W. R. WILLIS, M. T. ROBINSON, J. App1. Phys. 34, 153 (1963.

17. A. R. KRAUSS and D. M. GRUEM, J. Nucl. Mat, $\mathrm{T}$, $55 \& 86,1179$ (1979).

18. A. R. KRAUSS, D. A. GRUEN, and A. B. DEWALD, J. Nucl. Mater., 121, 398 (1984). 